\title{
ARTICLE
}

\section{Can metal-tolerant endophytic biocontrol agents promote plant-growth under metal stress?}

\author{
Carrie Siew Fang Sim ${ }^{1,2}$, Yuen Lin Cheow ${ }^{1}$, Si Ling Ng${ }^{3}$, Adeline Su Yien Ting 1,2* \\ 1 School of Science, Monash University Malaysia, Jalan Lagoon Selatan, 47500 Bandar Sunway, Selangor, Malaysia. \\ 2 Tropical Medicine and Biology Multidisciplinary Platform, Monash University Malaysia, Jalan Lagoon Selatan, \\ 47500 Bandar Sunway, Selangor, Malaysia. \\ ${ }^{3}$ School of Chemical Sciences, Universiti Sains Malaysia, 11800 USM, Penang, Malaysia.
}

\begin{abstract}
Five metal-tolerant endophytic isolates (Bipolaris sp. LF7, Diaporthe miriciae LF9, Trichoderma asperellum LF11, Phomopsis asparagi LF15, Saccharicola bicolor LF22), with known metal-tolerance attributes and biocontrol activities against Ganoderma boninense, were tested for growth-promoting activities independent of (in vitro) and associated with plants (height, weight, root mass and stem circumference) (in vivo). Results revealed that metal-tolerant endophytes did not significantly render benefit to host plants as plant growth was compromised by the presence of metals. Lower production of indole-acetic acid (0.74-21.77 $\left.\mathrm{g} \mathrm{m} \mathrm{m}^{-1}\right)$, siderophores (8.82-90.26\%), and deaminase activities of 1-aminocyclopropane carboxylic acid (3.00-69.2 $\mu \mathrm{mol} \mathrm{mg}$ protein $\left.{ }^{-1} \mathrm{hr}^{-1}\right)$ were observed.

Acta Biol Szeged 63(2):169-179 (2019)
\end{abstract}

\section{KEY WORDS}

1-aminocyclopropane carboxylic acid deaminase

growth parameterr

indole-acetic acid

phosphate solubilisation

plant hormone

siderophore

\section{ARTICLE INFORMATION}

Submitted

10 February 2020

Accepted

6 March 2020

*Corresponding author

E-mail: adelsuyien@yahoo.com adeline.ting@monash.edu

\section{Introduction}

Endophytes are a group of microorganisms known to colonize plant tissues asymptomatically. They render numerous benefits to the host plants, which include protecting host plants against pathogens, herbivores and insect pests (Rúa et al. 2013); enhancing tolerance towards unfavourable environmental conditions (Naveed et al. 2014; Zhang et al. 2011); and stimulating plant growth (Nascimento et al. 2016). Endophytes that are biocontrol agents (BCAs), typically have multiple mechanisms to suppress pathogen; via inhibitory compounds, induced host resistance, and by improving growth and vigour of host plants.

Several endophytic species have been reported to stimulate plant growth successfully. They include Penicillium chrysogenum, P. crustosum, Piriformospora indica, Serratia quinivorans, Bacillus cereus, B. subtilis, Pseudomonas aeruginosa and Pantoea amanatis (Sirrenberg et al. 2007; Nascimento et al. 2016; Hassan 2017; Wu et al. 2018). These endophytes stimulate plant growth by solubilising phosphate (P. chrysogenum, P. crustosum, B. cereus, B. subtilis), producing iron-chelating siderophores (Ps. aeruginosa), producing indole-acetic acid to stimulate root growth (Pi. indica), and by modulation of the hormone ethylene via the deaminase activity of 1-aminocyclopropane carboxylic acid (Pa. amanatis). Improved plant growth is important as it contributes to plant vigour and delays disease progression and the onset of disease symptoms (Ting 2014).

In this study, the growth-promoting activities of metal-tolerant endophytes were investigated under metal stress. Metal-tolerant endophytes are a new group of biocontrol agents that are hypothesized to render benefits to host plants in metal-laden soils. In earlier studies, these metal-tolerant endophytes were discovered to demonstrate biocontrol activities towards Ganoderma boninense, a causal agent of Basal Stem Rot disease of oil palm (Sim et al. 2019a, 2019b, 2019c). In those studies, the mechanisms of action were attributed to antifungal compounds produced. For this study, the ability of metal-tolerant endophytes in promoting plant-growth is determined. This observation is important as it suggests the potential role of metal-tolerant endophytic biocontrol agents in enhancing plant growth in the presence of metals and pathogen. Furthermore, various landscapes are now being used for oil palm planting; from desirable inland top-soils, to undesirable peat swamp and acid sulphate 
soils. While inland terrain soils are suitable soils, peat and acid sulphate soils are acidic and has bioavailable forms of metal cations such as copper $\left(\mathrm{Cu}^{2+}\right)$, lead $\left(\mathrm{Pb}^{2+}\right)$, zinc $\left(\mathrm{Zn}^{2+}\right)$ and cadmium $\left(\mathrm{Cd}^{2+}\right)$, prompting the exploration of metal-tolerant endophytes. According to Zarcinas et al. (2004), $\mathrm{Cu}^{2+}$ levels in soils were between $10.1-47.2 \mathrm{mg}$ $\mathrm{kg}^{-1}$, for $\mathrm{Zn}^{2+}$ between 27.6-40.0 $\mathrm{mg} \mathrm{kg}^{-1}$, for $\mathrm{Pb}^{2+}$ between 23.9-29.0 $\mathrm{mg} \mathrm{kg}^{-1}$, and between $0.1-0.4 \mathrm{mg} \mathrm{kg}^{-1}$ for $\mathrm{Cd}^{2+}$. With the presence of metals in soils, plant growth is generally affected due to metal toxicity. Therefore, to mitigate this, metal-tolerant endophytes with plant growth promoting properties (in addition to biocontrol potential) are investigated for potential as biocontrol agents. This is to enable the management of disease via plant growth promotion, albeit under metal stress conditions.

This study aims to establish the role of these endophytes in promoting plant growth, and this was evaluated under the influence of metal-stress, as the endophytes used are metal-tolerant endophytes. The endophytes were first tested via in vitro assays to determine their expression of plant growth-promoting attributes. The endophytes were exposed to conditions with and without metal stress, and the productions of the following compounds (or their activities) were quantified: indole-acetic acid (IAA), siderophore, phosphate solubilisation, and deaminase activity of 1-aminocyclopropane carboxylic acid (ACC). Two isolates with the most promising activities were subsequently selected for inoculation to oil palm ramets to validate their impact on growth (height, weight, root mass and stem circumference). This study is one of the few publications documenting the influence of metals on the growth-promoting activities of metal-tolerant biocontrol endophytes. This provides an overview of the possible use of these endophytes to improve plant growth and vigour, and in suppressing disease in metal-laden soils.

\section{Materials and methods}

Both in vitro and in vivo tests were performed to evaluate the growth promoting activities of the metal-tolerant biocontrol endophytes. The in vitro tests involved quantification of indole-acetic acid (IAA), siderophore production, phosphate solubilisation, and deaminase activity of 1-aminocyclopropane carboxylic acid (ACC) produced by the endophytes. In the in vivo assessment, growth parameters such as height, weight, root mass and stem circumference were measured to determine plant-growth promoting activities of two selected endophytes. Both in vitro and in vivo tests were carried out in conditions under metal-stress and in the absence of metal stress.

Culture establishment of endophytes and preparation

\section{of metal solutions}

Five metal-tolerant endophytes previously identified by Sim et al. (2018) as Bipolaris sp. LF7 (GenBank accession no. KX510121), Diaporthe miriciae LF9 (GenBank accession no. KX398059), Trichoderma asperellum LF11 (GenBank accession no. KX510127), Phomopsis asparagi LF15 (GenBank accession no. KX510125) and Saccharicola bicolor LF22 (GenBank accession no. KX510132), were selected for this study. These endophytes were isolated from the phytoremediator plant Phragmites sp. and demonstrated strong antifungal activities towards the pathogen Ganoderma boninense: they were able to suppress disease development when applied to oil palm seedlings (Sim et al. 2019a, 2019b). The isolates were cultured, incubated and maintained on Potato Dextrose Agar (PDA, Merck) (7 days, $25 \pm 2{ }^{\circ} \mathrm{C}$ ) for subsequent tests.

Stock solutions of various metal solutions were prepared to $1000 \mathrm{mg} \mathrm{L}^{-1}$. This includes for $\mathrm{Cd}\left(\mathrm{NO}_{3}\right)_{2} \cdot 4 \mathrm{H}_{2} \mathrm{O}$ (Aldrich Chemical), $\mathrm{Cu}\left(\mathrm{NO}_{3}\right)_{2} \cdot 3 \mathrm{H}_{2} \mathrm{O}$ (Riendemann Schmidt Chemical), $\mathrm{Pb}\left(\mathrm{NO}_{3}\right)_{2}$ (Emsure) and $\mathrm{Zn}\left(\mathrm{NO}_{3}\right)_{2} \cdot 6 \mathrm{H}_{2} \mathrm{O}$ (R\&M Chemicals). Prepared stock solutions were diluted to concentrations of 10 and $25 \mathrm{mg} \mathrm{L}^{-1}$ (additional $50 \mathrm{mg} \mathrm{L}^{-1}$ for $\mathrm{Cu}^{2+}$ ). The working solutions was adjusted to $\mathrm{pH} 5$ using $0.1 \mathrm{M} \mathrm{HCl}$ and $0.1 \mathrm{M} \mathrm{NaOH}$.

\section{Production of indole-acetic acid (IAA)}

Three mycelial plugs of each endophyte (5 $\mathrm{mm}$ diameter) were inoculated into $100 \mathrm{~mL}$ of Potato Dextrose Broth (PDB, Merck) supplemented with $100 \mathrm{mg} \mathrm{L}^{-1}$ tryptophan and incubated at $25 \pm 2{ }^{\circ} \mathrm{C}$ for 28 days. After every 7-day interval, $5 \mathrm{~mL}$ of the culture was pipetted into a falcon tube and centrifuged $\left(25 \pm 2{ }^{\circ} \mathrm{C}, 12000 \mathrm{rpm}, 10 \mathrm{~min}\right)$. The supernatant $(1 \mathrm{~mL})$ was collected, mixed with $2 \mathrm{~mL}$ of Salkowski reagent, and incubated in the dark for 20 min prior to absorbance measurement at $535 \mathrm{~nm}$ (Babu et al. 2014). Standard curves were constructed from concentrations of $0-100 \mu \mathrm{g} \mathrm{mL}^{-1}$ and the IAA produced by the endophytes was determined. The influence of metals on the production of IAA was assayed by preparing a similar experimental set-up. The difference in this set-up is that that isolates were cultured in PDB supplemented with $\mathrm{Cu}^{2+}, \mathrm{Pb}^{2+}, \mathrm{Zn}^{2+}, \mathrm{Cd}^{2+}$ (at concentrations of 10 and $25 \mathrm{mg}$ $\mathrm{L}^{-1}$ for each metal, an additional $50 \mathrm{mg} \mathrm{L}^{-1}$ for $\mathrm{Cu}^{2+}$ ). The supernatant obtained were subjected to similar assay conditions.

\section{Production of siderophore}

Production of siderophore by the endophytes was determined via qualitative and quantitative assays. For qualitative analysis, Chrome azurol S (CAS) was used as an indirect method to indicate the production of siderophore. This dye competes with siderophores for iron. The endophytes were first qualitatively assessed 
for siderophore production using the modified half CAS blue agar method (Machuca and Milagres 2003). The CAS blue agar was prepared according to Louden et al. (2011). Half of the agar (PDA) was cut and replaced with the CAS blue agar. The mycelial plug of the endophyte (5 mm diameter) was subsequently inoculated onto the PDA and incubated ( 28 days, $25 \pm 2{ }^{\circ} \mathrm{C}$ ). At every 7-day interval for the next 28 days, colour changes of the CAS agar were observed and measured. Deep colourisation of the CAS dye indicated that more iron bonded to the dye due to lesser siderophore production/competition. In contrast, lighter dye intensity indicated higher siderophore production/competition as less iron is available to bind to the dye (lighter intensity). This reflected that more iron is uptake by siderophores. The influence of metals on the production of siderophore was determined by preparing a similar CAS blue agar set-up, with the CAS agar supplemented with $\mathrm{Cu}^{2+}, \mathrm{Pb}^{2+}, \mathrm{Zn}^{2+}, \mathrm{Cd}^{2+}$ at 10 and $25 \mathrm{mg} \mathrm{L}^{-1}$ (and an additional $50 \mathrm{mg} \mathrm{L}^{-1}$ for $\mathrm{Cu}^{2+}$ ).

The siderophore production by endophytes was also quantified. This quantitative assay is a less common approach used compared to the qualitative CAS blue agar technique. Nevertheless, it allows for the quantification of siderophores for comparative purpose. Three mycelial plugs of each endophyte were firstly inoculated into 100 $\mathrm{mL}$ PDB ( 28 days, $25 \pm 2{ }^{\circ} \mathrm{C}$ ). At every 7-day interval for the following 28 days, $1 \mathrm{~mL}$ of the supernatant was mixed with $1 \mathrm{~mL}$ of CAS solution and incubated for $60 \mathrm{~min}$. Absorbance was read at $630 \mathrm{~nm}$ and siderophore production (\%) was determined (Eq. 1) (Machuca and Milagres 2003). The influence of metals on the production of siderophore in broth was evaluated by preparing a similar set-up, using supernatant recovered from cultures established in PDB supplemented with $\mathrm{Cu}^{2+}, \mathrm{Pb}^{2+}, \mathrm{Zn}^{2+}, \mathrm{Cd}^{2+}$ at 10 and $25 \mathrm{mg}$ $\mathrm{L}^{-1}$ (and an additional $50 \mathrm{mg} \mathrm{L}^{-1}$ for $\mathrm{Cu}^{2+}$ ).

Production of siderophore $(\%)=$

(Initial absorbance-Absorbance of sample)

Initial absorbance $\times 100$

Production of siderophore $(\%)=($ Initial absorbanceAbsorbance of sample) / Initial absorbance $\times 100 \%$

\section{Phosphate solubilisation}

The endophytes (mycelial plug, $5 \mathrm{~mm}$ diameter) were inoculated onto Pikovskya's agar (HiMedia Laboratories) and incubated ( 28 days, $25 \pm 2{ }^{\circ} \mathrm{C}$ ). Phosphate solubilisation is indicated by the formation of a clear halo zone on the agar. The phosphate solubilisation capacity of the endophytes is quantified as phosphate solubilizing efficiency
(SE, \%) (Eq. 2). The SE (\%) were observed for day $7^{\text {th }}, 14^{\text {th }}$ , $21^{\text {st }}$ and $28^{\text {th }}$ (Srivastav et al., 2004). To determine phosphate solubilisation activities of endophytes under metal stress, the procedure was repeated using Pikovskya's agar supplemented with $\mathrm{Cu}^{2+}, \mathrm{Pb}^{2+}, \mathrm{Zn}^{2+}, \mathrm{Cd}^{2+}$ (at 10 and $25 \mathrm{mg}$ $\mathrm{L}^{-1}$, and an additional $50 \mathrm{mg} \mathrm{L}^{-1}$ for $\mathrm{Cu}^{2+}$.

Solubilising efficiency $(\mathrm{SE})(\%)=$

(Diameter of solubilization zone-Diameter of colony) Diameter of colony $\times 100$

Solubilising efficiency $(\mathrm{SE})(\%)=($ Diameter of solubilization zone-Diameter of colony) / Diameter of colony $\times 100$

\section{Deaminase activity of 1-aminocyclopropane carboxylic acid (ACC) of endophytes}

Three mycelial plugs ( $5 \mathrm{~mm}$ diameter) of each endophyte were inoculated into flasks containing $100 \mathrm{~mL}$ PDB $(28$ days, $25 \pm 2{ }^{\circ} \mathrm{C}$ ). The culture was allowed to grow and the mycelium was then filtered. The filtrate was collected and $200 \mu \mathrm{L}$ was pipetted and reacted with $25 \mu \mathrm{L}$ toluene and vortexed for $30 \mathrm{sec}$ (Saleh and Glick 2001). Then, $20 \mu \mathrm{L}$ of $0.45 \mathrm{M}$ ACC of the enzyme ACC was added and incubated at $30^{\circ} \mathrm{C}$. After $10 \mathrm{~min}$, the reaction was stopped with $1 \mathrm{~mL}$ of $0.56 \mathrm{~N} \mathrm{HCl}$. The lysates were centrifuged $(10000 \mathrm{~g}, 10 \mathrm{~min})$, and $1 \mathrm{~mL}$ of the supernatant was pipetted and mixed with $800 \mu \mathrm{L}$ of $0.56 \mathrm{~N} \mathrm{HCl}$ and $300 \mu \mathrm{L}$ of 2,4-dinitrophenylhydrazine. The mixture was incubated $\left(30 \mathrm{~min}, 30^{\circ} \mathrm{C}\right)$ and added with $2 \mathrm{~mL}$ of $2 \mathrm{~N}$ $\mathrm{NaOH}$. The absorbance was measured at $540 \mathrm{~nm}$ and the ACC deaminase activity was calculated based on standard curves constructed. The ACC deaminase activities by endophytes under the influence of metals was assayed by preparing a similar set-up, using endophyte suspension recovered from cultures established in PDB supplemented with $\mathrm{Cu}^{2+}, \mathrm{Pb}^{2+}, \mathrm{Zn}^{2+}, \mathrm{Cd}^{2+}$ at 10 and $25 \mathrm{mg} \mathrm{L}^{-1}$ (and an additional $50 \mathrm{mg} \mathrm{L}^{-1}$ for $\mathrm{Cu}^{2+}$ ). The assay was carried out in a similar manner.

\section{In vivo plant growth promoting activities of selected endophytes}

Two endophytic isolates (D. miriciae LF9 and T. asperellum LF11) with the most promising results observed from the in vitro assays were selected. The isolates were first cultured in $250 \mathrm{~mL}$ PDB (14 days, $25 \pm 2{ }^{\circ} \mathrm{C}$ ). The mycelium was then homogenized using LabGen 125 homogenizer (Cole-Parmer, USA) and the homogenized mycelium was adjusted to a concentration of $10^{6}$ of colony forming unit ( $\mathrm{cfu} \mathrm{mL}^{-1}$ ) each. The adjusted inoculums were prepared in $100 \mathrm{~mL}$ and were used to inoculate the 


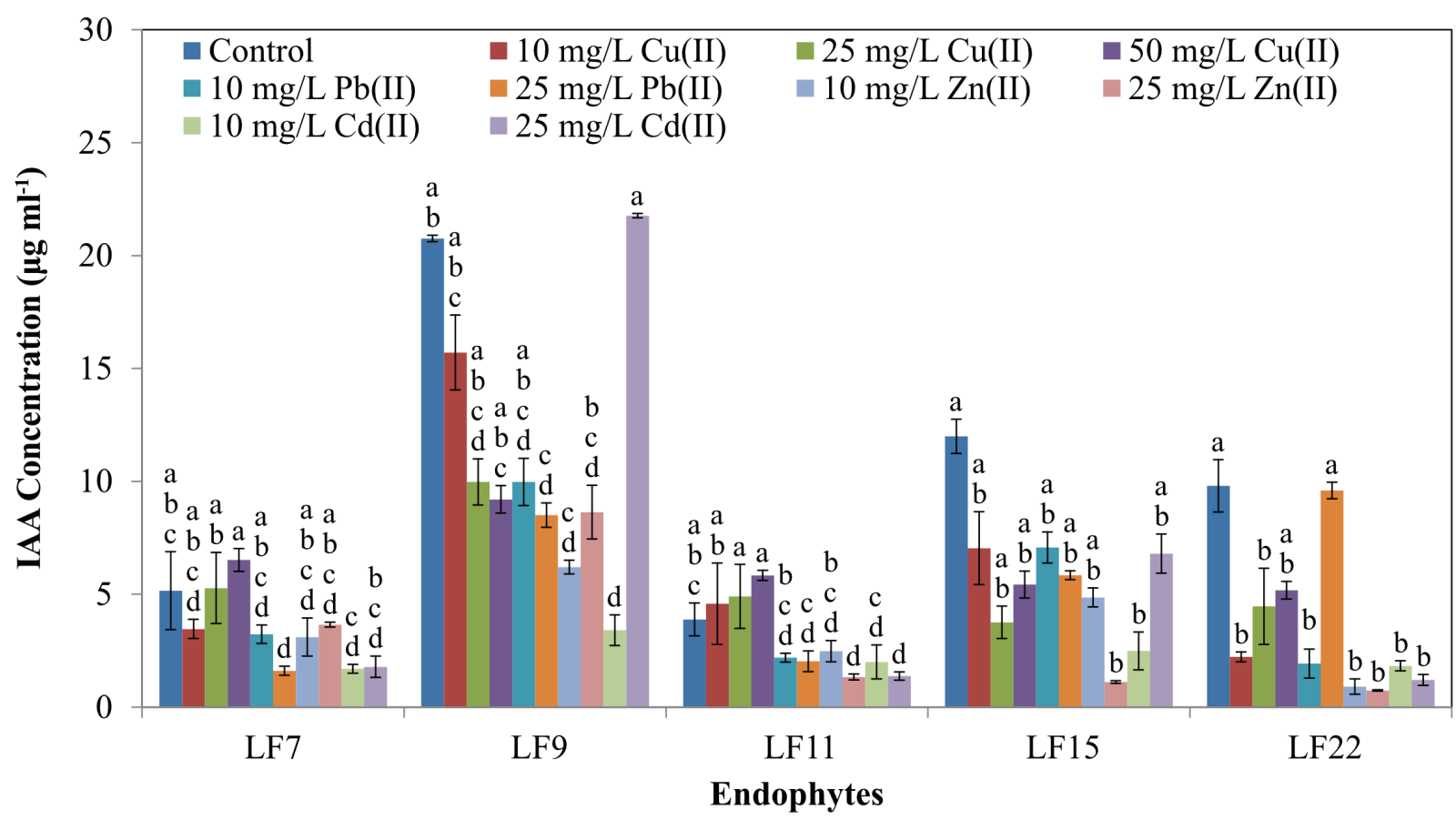

Figure 1. Indole-acetic acid (IAA) ( $\left.\mu \mathrm{g} \mathrm{mL} \mathrm{L}^{-1}\right)$ produced by metal-tolerant endophytes (Bipolaris sp. LF7, D. miriciae LF9, T. asperellum LF11, P. asparagi LF15, S. bicolor LF22) after 28 days incubation with exposure to $\mathrm{Cu}^{2+}, \mathrm{Pb}^{2+}, \mathrm{Zn}^{2+}$ and $\mathrm{Cd}^{2+}$. Controls were incubations without metal supplementation. Bars indicate standard deviations of means $( \pm S D)$. Means with the same letters for each isolate are not significantly different $\left(\mathrm{HSD}_{(0.05)}\right)$.

soils via soil-drenching. The tissue-cultured ramets, at 3-4 leaf stage and 14-16 cm in height, were then planted into the drenched soils and allowed to grow in shade (28 $\pm 2{ }^{\circ} \mathrm{C}, 12 \mathrm{~h}$ photoperiod). For control, soil drenching was performed using sterile distilled water. Solutions for each metal $\left(\mathrm{Cu}^{2+}, \mathrm{Pb}^{2+}, \mathrm{Zn}^{2+}, \mathrm{Cd}^{2+}\right.$ at 10 and $25 \mathrm{mg} \mathrm{L}^{-1}$; additional $50 \mathrm{mg} \mathrm{L}^{-1}$ for $\mathrm{Cu}^{2+}$ ) were used to water the soil to create metal-laden soils. Controls were established with endophyte-free ramets watered using sterile distilled water. Growth parameters such as height, weight, root mass and stem circumference were measured at $7^{\text {th }}, 14^{\text {th }}$, $21^{\text {st }}$ and $28^{\text {th }}$ day.

\section{Statistical analysis}

All the experiments/assays were carried out in triplicates, with data analysed using ANOVA (Analysis of Variance). The means and standard deviations were compared with Tukey comparisons $\left(\mathrm{HSD}_{(0.05)}\right)$ using the Statistical Packaging for the Social Science (SPSS) (software version 20.0).

\section{Results and Discussion}

\section{Production of indole-acetic acid (IAA)}

Lower levels of IAA were produced by endophytes subjected to metal stress $\left(0.74-21.77 \mu \mathrm{g} \mathrm{mL}^{-1}\right)$ compared to non-metal conditions (control) (3.88-20.76 $\mu \mathrm{g} \mathrm{mL}-1$ ). Among the isolates tested, $D$. miriciae LF9 was the least affected (3.41-21.77 $\mu \mathrm{g} \mathrm{mL}^{-1}$ IAA production) whilst $T$. asperellum LF11 was the most susceptible to presence of metals as minimal IAA levels were detected (1.33-5.83 $\mu \mathrm{g}$ $\mathrm{mL}^{-1}$ ) (Fig. 1). In the absence of metals, higher IAA production by $D$. miriciae LF9 $\left(20.76 \mu \mathrm{g} \mathrm{mL}^{-1}\right)$, $P$. asparagi LF15 $\left(11.99 \mu \mathrm{g} \mathrm{mL}^{-1}\right)$, S. bicolor LF22 $\left(9.80 \mu \mathrm{g} \mathrm{mL}^{-1}\right)$, Bipolaris sp. LF7 $\left(5.16 \mu \mathrm{g} \mathrm{mL}^{-1}\right)$ and T. asperellum LF11 $\left(3.88 \mu \mathrm{g} \mathrm{mL}^{-1}\right)$ (Fig. 1) were detected. This suggested that the production of IAA and subsequently their growth promoting effect was influenced by the presence/absence of metals. Nevertheless, the production of IAA by all isolates under metal stress were somewhat maintained throughout the 28 days (Supplementary Fig. 1), although the IAA levels were lower than observations from endophytes in nonmetal conditions.

It was evident that metals affected the production of IAA by the isolates. This was also observed by Acuna et al. (2011) in which the presence of metals such as Fe and Al reduced IAA production by Bacillus sp. and Paenibacillus sp.. The reduction in IAA production under metal stress was presumably attributed to the complexation of metal cations with IAA (Du et al. 2011). This suggested that metals lowered the production of IAA, hampering root elongation (Hilbert et al. 2012; Sukumar et al. 2012) and 
Table 1 Chrome Azurol S (CAS) reaction rates of the isolates ( $\mathrm{mm} /$ day) under the influence of metals after 28 days.

\begin{tabular}{|c|c|c|c|c|c|c|c|c|c|c|}
\hline \multirow{3}{*}{ Endophytes } & \multicolumn{10}{|c|}{ Metal concentrations $\left(\mathrm{mg} \mathrm{L}^{-1}\right)$} \\
\hline & $\mathrm{Cu}$ & & & $\mathrm{Pb}$ & & $\mathrm{Zn}$ & & Cd & & Control \\
\hline & 10 & 25 & 50 & 10 & 25 & 10 & 25 & 10 & 25 & 0 \\
\hline Bipolaris sp. LF7 & \pm & \pm & \pm & \pm & \pm & \pm & \pm & \pm & \pm & \pm \\
\hline D. miriciae LF9 & \pm & \pm & \pm & \pm & + & + & + & + & + & + \\
\hline T. asperellum LF11 & \pm & \pm & \pm & + & + & \pm & + & + & + & + \\
\hline P. asparagi LF15 & \pm & \pm & \pm & \pm & \pm & + & \pm & + & + & \pm \\
\hline S. bicolor LF22 & \pm & \pm & \pm & \pm & \pm & \pm & \pm & \pm & \pm & \pm \\
\hline
\end{tabular}

Note: \pm for rates $<0.5 \mathrm{~mm} /$ day (mild) and + for rates between 0.5-1.0 mm/day (moderate)

consequently implicating water and nutrient uptake. It was also interesting to note that the metal tolerance attributes of the endophytes, did not render "immunity" to the isolates from the influence of metals on IAA production.

The production of IAA as a growth-promoting factor has been reported in various species of Trichoderma and Phomopsis. The low levels of IAA produced by T. asperellum LF11 (highest at $5.83 \mu \mathrm{g} \mathrm{mL} \mathrm{L}^{-1}$ IAA) was similar to observations by Gravel et al. (2007) that showed T. atroviride (another species of Trichoderma) producing only $6.20 \mu \mathrm{g}$ $\mathrm{mL}^{-1}$ IAA. The production of IAA by $P$. asparagi LF15 in this study further strengthen the IAA-producing capacity of Phomopsis sp. This was also observed by Chen et al. (2011) and Chithra et al. (2017) in Phomopsis sp. isolated from Piper nigrum, and P. liquidambari from Bischofa polycarp, respectively. On the contrary, IAA production by $S$. bicolor LF22, D. miriciae LF9 as well as Bipolaris sp. LF7, were detected and reported for the first time. To summarize, results here highlighted that presence of metals generally reduced the production of IAA in endophytes, subsequently leading to absence or weak stimulation of root growth in the presence of metals. And the metal-tolerant endophytes were also not exempted from this metal-IAA production interaction.

\section{Production of siderophore}

The plate assay revealed that in the presence of metals, the reaction rates by $D$. miriciae LF9 and $T$. asperellum LF11 were generally moderate $(0.5-1.0 \mathrm{~mm} /$ day $)$ whilst Bipolaris sp. LF7, P. asparagi LF15 as well as S. bicolor LF22 showed mild CAS reaction rates $(<0.5 \mathrm{~mm} /$ day) (Table 1). The reaction rates remained throughout the 28 days (Supplementary Table 1). The reaction rates for endophytes in CAS plates without metals remained similar as well (Table 1). Since the observation using CAS blue agar was deemed to be preliminary, presumptive and inconclusive, the quantitative test was performed.

The quantification of siderophore production revealed that under the influence of various metals, siderophore production was generally lower $(8.82-90.26 \%)$ in most endophytes (except T. asperellum LF11) compared to non-metal solutions (66.75-84.44\%). Isolates S. bicolor LF22, P. asparagi LF15, D. miriciae LF9 and Bipolaris sp. LF7, were susceptible to the presence of some of the metals, resulting in lower siderophore production; ranging from 8.82-80.51\%, 0.08-78.20\%, 32.81-76.05\% and $21.94-78.24 \%$, respectively (Fig. 2). In the absence of metals, siderophore production was generally higher for all isolates; T. asperellum LF11 (84.44\%), P. asparagi LF15 (75.92\%), D. miriciae LF9 (74.32\%), Bipolaris sp. LF7 (73.70\%) and S. bicolor LF22 (66.75\%) (Fig. 2). Among the isolates, only isolate $T$. asperellum LF11 appeared to be less susceptible to metals with levels of siderophore production (19.21-90.26\%) comparable to control. Nevertheless, siderophore production was maintained throughout the 28 days for the isolates, even in the presence of metal stress (Supplementary Fig. 2). The discovery of siderophore production by $P$. asparagi LF15, D. miriciae LF9, Bipolaris sp. LF7 and S. bicolor LF22 are relatively novel as limited reports are available on this. By contrast, the siderophore-producing attribute in T. asperellum LF11, is well known as it has been reported for other Trichoderma sp. such as Trichoderma virens (Babu et al.2014). Trichoderma spp. are one of the most common filamentous fungi with siderophore-producing capacity, alongside Aspergillus spp. and Penicillum menonorum (Babu et al. 2015; Machuca and Milagres 2003).

The CAS assays also revealed that in some instances, the colour intensity does not reflect the CAS production of the endophytes. The lower concentrations of siderophore (from liquid medium) recorded, were attributed to the nature of this compound to form complexes with other metal cations other than the desired iron $\left(\mathrm{Fe}^{2+}\right)$ (Dimkpa et al. 2008; Aguado-Santacruz et al. 2012). Since metal cations are abundant in this study, the siderophores could have bind easily to any cations supplemented $\left(\mathrm{Cu}^{2+}, \mathrm{Pb}^{2+}\right.$, $\mathrm{Zn}^{2+}, \mathrm{Cd}^{2+}$ ). The ability of siderophores to bind to metal cations not only aids in enhancing tolerance to metal-stress conditions, it is also a means of bioremediation. This mechanism has been exploited to bind toxic metals and consequently removing the toxic metals from the 
environment. Thus, siderophore production is a highly valuable trait for biocontrol agents applied to metal-laden soils. With the production of siderophores, the biocontrol agents is expected to ameliorate the soil environment as toxic metals are removed, thus improving survivability of plants in metal-contaminated sites. Siderophores produced by biocontrol agents also deprives iron from pathogens, thus suppressing the growth of pathogens (Verma et al. 2011; Yu et al. 2011; Beneduzi et al. 2012).

\section{Phosphate solubilisation}

Four of the five endophytic isolates solubilised phosphate, in both the presence or absence of metals. Formation of clear halo zones was detected on Pikovskya's agar with and without metal supplementation. Results further suggested that phosphate solubilisation by the endophytes were higher in the presence of metals (3.94-79.82\%) than in non-metal (17.64-20.83\%) conditions. Higher phosphate solubilisation efficiency under metal stress was demonstrated by P. asparagi LF15 (18.81-79.82\%) (Fig. 3). Solubilisation of phosphate was also regulated by $D$. miriciae
LF9 (12.43-56.24\%), Bipolaris sp. LF7 (3.94-34.00\%) and T. asperellum LF11 (12.44-22.07\%) (Fig. 3). The gradual increase in phosphate solubilisation by the isolates was observed throughout the 28 days (Supplementary Fig. 3). By contrast, the absence of metals resulted in inferior phosphate solubilisation activities by $D$. miriciae LF9 (20.83\%), followed by P. asparagi LF15 (18.4\%) and Bipolaris sp. LF7 (17.64\%) (after 28 days). Interestingly, phosphate solubilisation was, however, not observed in T. asperellum LF11 (Fig. 3) in the absence of metal stress (control). This is presumably due to the rapid growth rate of LF11 (to the extent of overgrowing) on the metal-free agar. Phosphate solubilisation was also absent in S. bicolor LF22, when cultured in the absence and presence of metals, as no formation of halo zones were detected. This suggested that the isolate $S$. bicolor LF22 is not a phosphate solubilizer.

The findings in this study, which showed endophytes (except S. bicolor LF22) having generally higher phosphate solubilisation under metal stress, agreed with ZúñigaSilva et al. (2015). Endophytes are proven to have similar capacity as other phosphate-solubilising fungi to solubilize

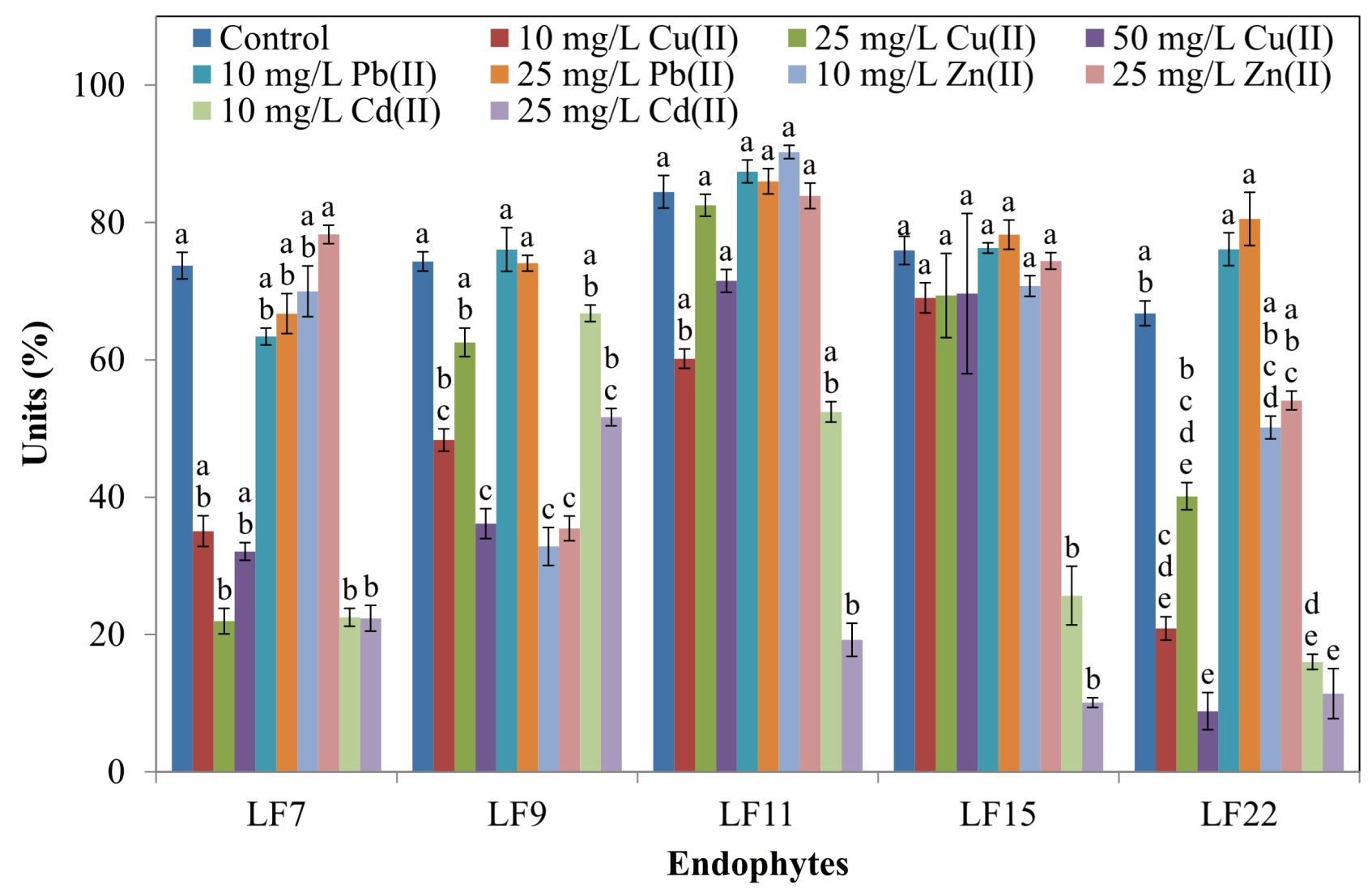

Figure 2. Siderophore production (\%) by metal-tolerant endophytes (Bipolaris sp. LF7, D. miriciae LF9, T. asperellum LF11, P. asparagi LF15, S. bicolor LF22) after 28 days incubation with exposure to $\mathrm{Cu}^{2+}, \mathrm{Pb}^{2+}, \mathrm{Zn}^{2+}$ and $\mathrm{Cd}^{2+}$. Controls were incubations without metal supplementation. Bars indicate standard deviations of means $( \pm S D)$. Means with the same letters for each isolate are not significantly different $\left(\operatorname{HSD}_{(0.05)}\right)$. 


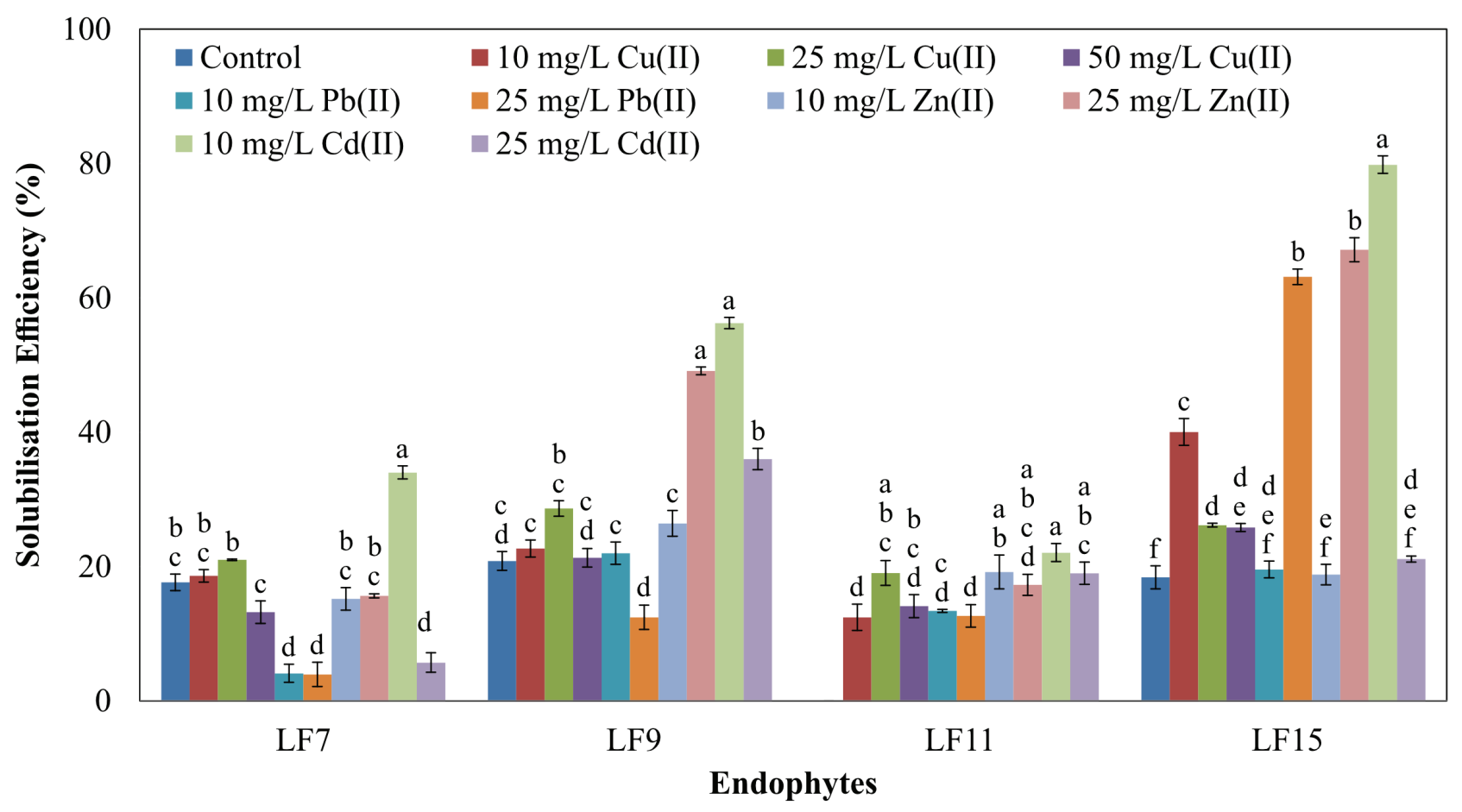

Figure 3. Phosphate solubilisation efficiency (\%) by metal-tolerant endophytes (Bipolaris sp. LF7, D. miriciae LF9, T. asperellum LF11, P. asparagi LF15, S. bicolor LF22) after 28 days incubation with exposure to $\mathrm{Cu}^{2+}, \mathrm{Pb}^{2+}, \mathrm{Zn}^{2+}$ and $\mathrm{Cd}^{2+}$. Controls were incubations without metal supplementation. Bars indicate standard deviations of means $( \pm S D)$. Means with the same letters for each isolate are not significantly different $\left(\mathrm{HSD}_{(0.05)}\right)$.

phosphate for uptake and use. Phosphate-solubilising fungi acidify and secrete siderophores to solubilize the naturally-limited phosphate into available forms, particularly in response to metal stress, and this ultimately results in the dissolution of bound phosphate (Walpola and Yoon 2013). This study has revealed for the first time, the phosphate-solubilising potential in endophytic Bipolaris sp. LF7, D. miriciae LF9 and $P$. asparagi LF15, as well as the non-phosphate solubilising activity of S. bicolor LF22. Existing literature on this is limited, although studies on phosphate-solubilizing by Trichoderma sp. has been reported. This study, which revealed phosphate solubilisation by $T$. asperellum LF11 in both the presence and absence of metals agreed with Zúñiga-Silva et al. (2015) (using T. atroviride), suggesting that phosphate solubilisation could be a common trait for Trichoderma sp.. In short, the endophytes tested in this study were able to solubilise phosphate in both conditions (in the absence and presence of metal stress), except for S. bicolor LF22. The increased phosphate-solubilising activities under metal stress conditions suggested higher phosphate acquisition by endophytes when applied in metal-laden soils.

\section{Deaminase activity of 1-aminocyclopropane carboxylic acid (ACC)}

This assay measures the $\alpha$-ketobutyrate, one of the prod- ucts of the 1-aminocyclopropane carboxylic acid (ACC) deaminase activity. It was revealed that ACC deaminase activity in endophytes were generally lower when exposed to metals (3.00-69.2 $\mu \mathrm{mol} \mathrm{mg}$ protein $\left.{ }^{-1} \mathrm{hr}^{-1}\right)$ as compared to the absence of metals (control) (19.17-54.30 $\mu \mathrm{mol} \mathrm{mg}$ protein $\left.{ }^{-1} \mathrm{hr}^{-1}\right)$. Among the five isolates tested, $T$. asperellum LF11 was the least susceptible to metal stress, exhibiting the highest ACC deaminase activity (8.69$69.2 \mu \mathrm{mol} \mathrm{mg}$ protein ${ }^{-1} \mathrm{hr}^{-1}$ ) especially in the presence of $\mathrm{Pb}$ and $\mathrm{Cd}$ (Fig. 4). The ACC deaminase activity by $T$. asperellum LF11 is comparable to other Trichoderma species, such as T. atroviride and T. virens (Babu et al. 2014; Gravel et al. 2007). On the contrary, presence of metals severely impacted ACC deaminase activity in the other endophytic isolates, particularly Bipolaris sp. LF7. This isolate produced the lowest ACC deaminase activities in the presence of metals (3.00-17.54 $\mu \mathrm{mol} \mathrm{mg} \mathrm{protein}{ }^{-1}$ $\mathrm{hr}^{-1}$ ) (Fig. 4). Presence of metals was less detrimental on the ACC deaminase activities of the other three isolates. Isolates $P$. asparagi LF15 (6.23-38.26 $\mu \mathrm{mol} \mathrm{mg} \mathrm{protein}{ }^{-1}$ $\left.\mathrm{hr}^{-1}\right)$, D. miriciae LF9 $\left(6.15-32.83 \mu \mathrm{mol} \mathrm{mg}\right.$ protein $\left.^{-1} \mathrm{hr}^{-1}\right)$ and S. bicolor LF22 (7.5-15.41 $\mu \mathrm{mol} \mathrm{mg} \mathrm{protein}{ }^{-1} \mathrm{hr}^{-1}$ ) (Fig. 4) retained their ACC deaminase activities under metal stress, but the activities were significantly lower compared to ACC deaminase activities in the absence of metal. In the absence of metals, the highest activity was observed for $D$. 


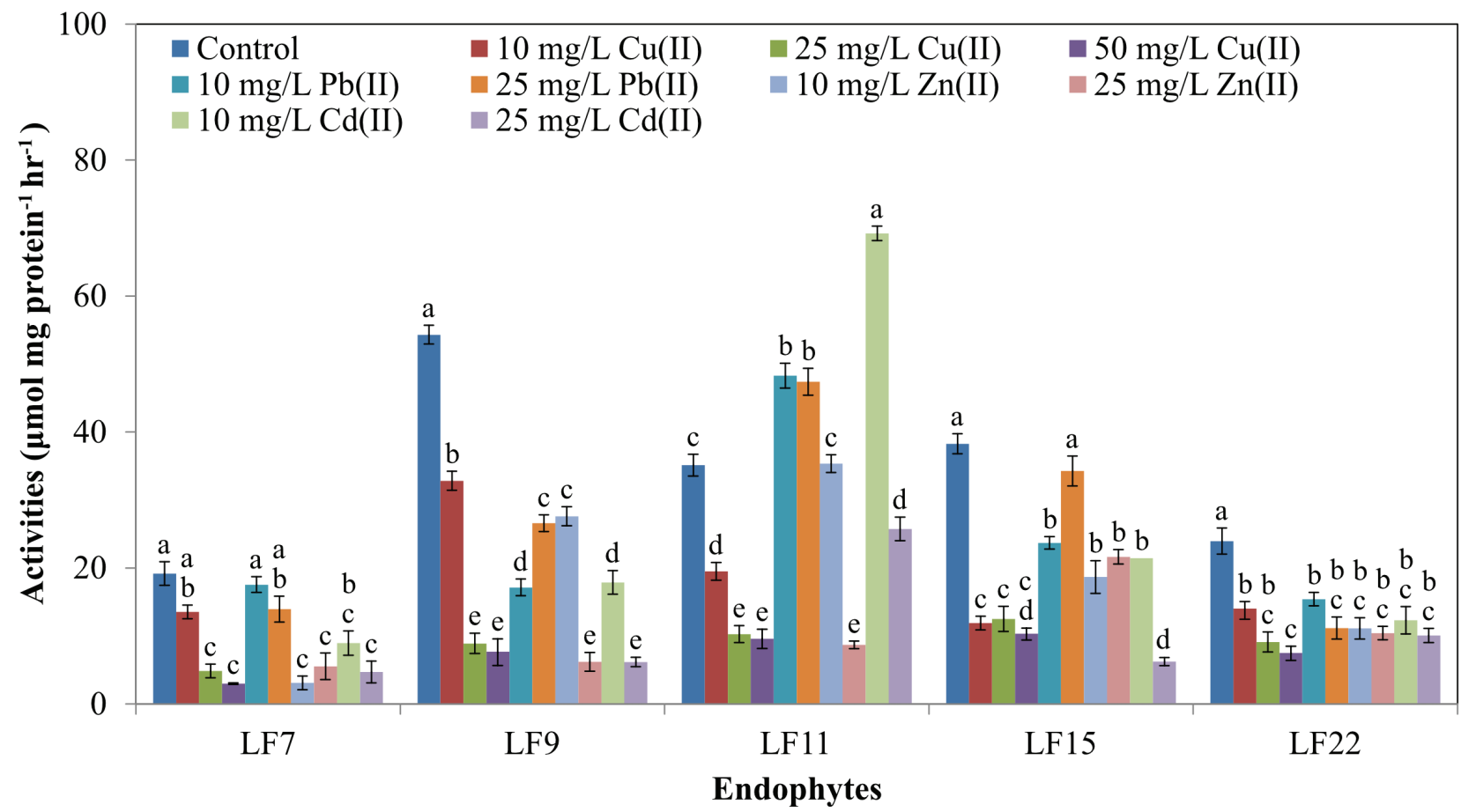

Figure 4. Activities of ACC deaminase ( $\mu$ mol protein $\mathrm{mg}^{-1} \mathrm{hr}^{-1}$ ) by metal-tolerant endophytes (Bipolaris sp. LF7, D. miriciae LF9, T. asperellum LF11, P. asparagi LF15, S. bicolor LF22) after 28 days incubation with exposure to $\mathrm{Cu}^{2+}, \mathrm{Pb}^{2+}, \mathrm{Zn}^{2+}$ and $\mathrm{Cd}^{2+}$. Controls were incubations without metal supplementation. Bars indicate standard deviations of means $( \pm S D)$. Means with the same letters for each isolate are not significantly different $\left(\operatorname{HSD}_{(0.05)}\right)$.

miriciae LF9 $\left(54.30 \mu \mathrm{mol} \mathrm{mg}\right.$ protein $\left.{ }^{-1} \mathrm{hr}^{-1}\right)$, followed by $P$. asparagi LF15 (38.26 $\left.\mu \mathrm{mol} \mathrm{mg} \mathrm{protein}{ }^{-1} \mathrm{hr}^{-1}\right)$, T. asperellum LF11 (35.11 $\left.\mu \mathrm{mol} \mathrm{mg} \mathrm{protein}{ }^{-1} \mathrm{hr}^{-1}\right)$, S. bicolor LF22 (23.95 $\mu \mathrm{mol} \mathrm{mg}$ protein $\left.{ }^{-1} \mathrm{hr}^{-1}\right)$ and Bipolaris sp. LF7 (19.17 $\mu \mathrm{mol}$ mg protein ${ }^{-1} \mathrm{hr}^{-1}$ ) (Fig. 4). Observations based on time intervals indicated that the ACC deaminase activities were lower in the initial stages, gradually increasing in the next 28 days (Supplementary Fig. 4).

The present study showed that ACC deaminase activities by the endophytes decreased when metals were present as a stress factor. The inhibition of ACC deaminase activities by metals was not specific to just fungal endophytes, as similar observations have been reported on bacteria. Carlos et al. (2016) discovered Serratia sp. strain Mc107, having lesser ACC deaminase activities when cultured in the presence of $\mathrm{Pb}^{2+}, \mathrm{Cu}^{2+}$ and $\mathrm{Cd}^{2+}$. Only Trichoderma species appeared to have ACC deaminase activities that were not implicated by presence of metals. Additionally, the initial decreasing trend of ACC deaminase activities followed by a gradual increase in activities follows the model described by Glick et al. (2007). According to the model, the initial decreasing trend was possibly associated with the reaction of ACC deaminase upon ACC to prevent the precursor from converting to ethylene. The activities gradually diminished throughout 21 days in this study, as lesser ACC was available. Following that, environmental stress (metals, in this study) may have triggered follow-up production of ACC (Yang and Hoffman 1984), consequently resulting in a rise in the activities of ACC deaminase. The increase in ACC deaminase activities was to prevent the build-up of the precursor ACC and their further conversion to ethylene. As such, ACC deaminase activities aid in reducing ethylene levels in plants, which enhances plant growth. In general, the decreased ACC deaminase activities of the endophytes under metal stress suggested lower phytohormone modulation in metal-contaminated soils, which could implicate plant growth.

\section{In vivo plant growth promoting activities of selected endophytes}

In non-metal soils, improved growth was observed in ramets treated with both selected endophytes $(D$. miriciae LF9 and T. asperellum LF11). Of the two isolates, inoculation with $D$. miriciae LF9 showed better growth of ramets with increased height $(4.68 \mathrm{~cm})$, weight $(1.14 \mathrm{~g})$, root growth $(0.39 \mathrm{~g})$ as well as stem circumference $(0.30$ $\mathrm{cm})$ (Fig. 5). Ramets inoculated with T. asperellum LF11 also exhibited similar positive influence; improved height $(3.90 \mathrm{~cm})$, weight $(0.94 \mathrm{~g})$, root mass $(0.32 \mathrm{~g})$ and stem circumference $(0.18 \mathrm{~cm})$ (Fig. 5). This further verified the 

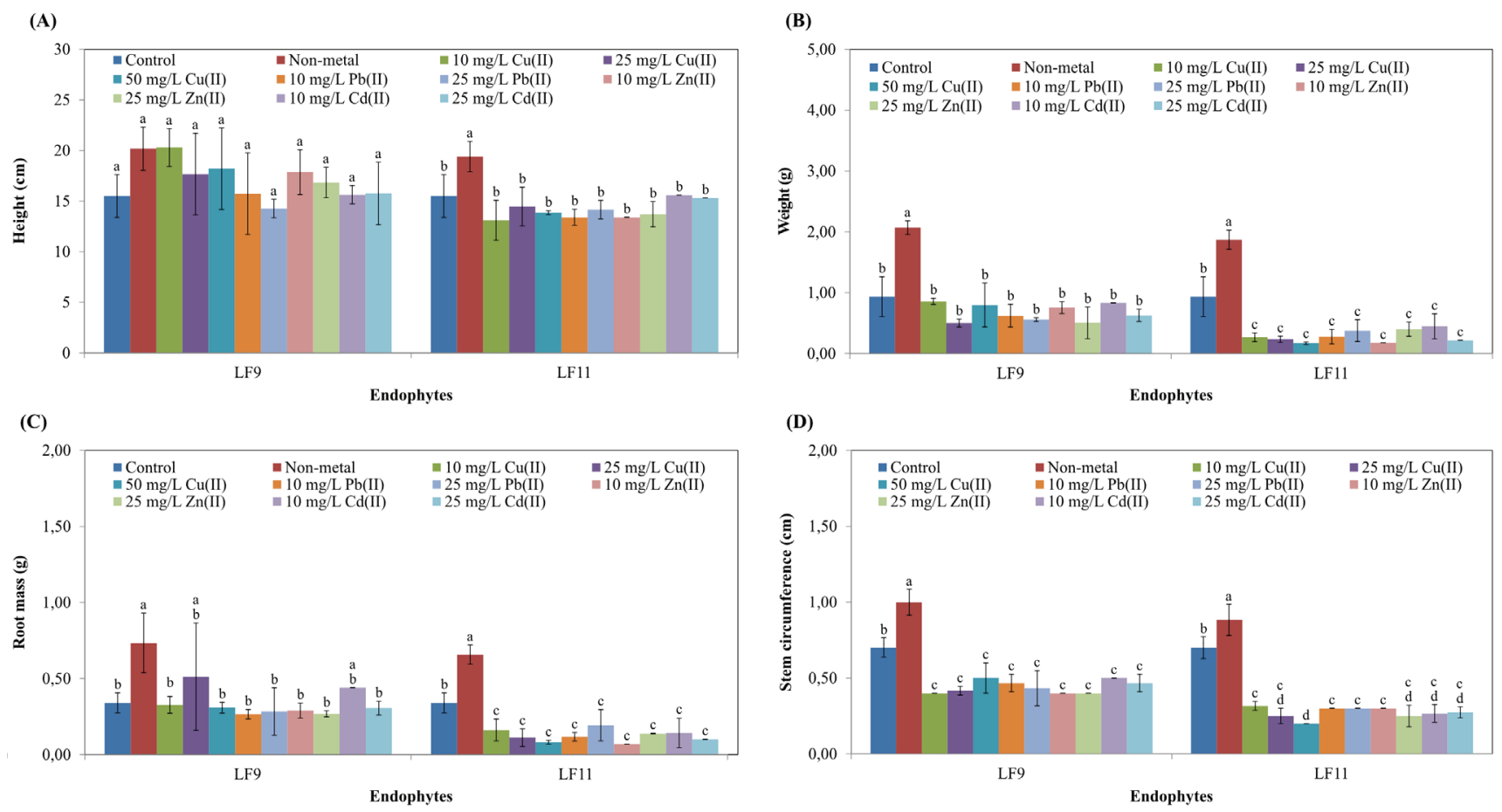

Figure 5. Growth parameters of (A) height (B) weight (C) root mass and (D) stem circumferences of ramets inoculated with metal-tolerant endophytes $D$. miriciae LF9 and $T$. asperellum LF11 in metal-laden soils consisting of $\mathrm{Cu}^{2+}, \mathrm{Pb}^{2+}, \mathrm{Zn}^{2+}$ and $\mathrm{Cd}^{2+}$. Controls were endophyte-free ramets watered with sterile distilled water. Bars indicate standard deviations of means $( \pm S D)$. Means with the same letters for each isolate are not significantly different $\left(\mathrm{HSD}_{(0.05)}\right)$.

growth-promoting ability of Trichoderma species, alongside T. atroviride, T. harzianum and T. psedokoningii, which were reported to effectively promote growth of tomato and maize (Babu et al. 2014; Gravel et al. 2007). However, in metal-laden soils, only D. miriciae LF9 appeared to have benefitted the ramets. Ramets inoculated with D. miriciae LF9 showed similar growth to ramets in non-metal soils with comparable height $(0.13-4.80 \mathrm{~cm})$, weight (0.08-0.43 g), and root mass (0.01-0.17 g) achieved. The stem circumference of the ramets was however affected $(0.20-0.30 \mathrm{~cm})$ (Figure 5). For ramets inoculated with $T$. asperellum LF11 and cultivated in soils with metals, poorer growth was observed compared to ramets in non-metal soils. In these ramets, inferior growth was evident with low growth measurements (height $0.10-2.4 \mathrm{~cm}$, weight $0.49-0.76 \mathrm{~g}$, root mass $0.15-0.27 \mathrm{~g}$ and stem circumference $0.38-0.50 \mathrm{~cm}$ ) recorded (Fig. 5).

The in vivo findings were aligned to the in vitro results, which revealed lesser growth promoting activities when endophytes were exposed to metals compared to non-metal conditions. Ramets inoculated with D. miriciae LF9 were less susceptible to metal stress, but ramets treated with $T$. asperellum LF11 were not able to tolerate metal stress and this affected the growth of the ramets (low weight, root mass and stem circumference). This also revealed that the association of Trichoderma species with host plant may not necessarily be beneficial in metal-laden soils. The poor growths observed in ramets grown in soils supplemented with metals, is attributed to the effect of metals in inhibiting the production of IAA, siderophore, and ACC deaminase activities by the endophytic biocontrol agents (albeit at varying degrees). In the instance where the growth-promoting attribute is not inhibited, ramets continued to grow well. This explains the continued growth of ramets inoculated with D. miriciae LF9, as the phosphate solubilisation activity of LF9 in metal soils was detectable. This study also revealed that despite of the metal-tolerant attributes of the endophytes (Sim et al. 2018, 2019a, 2019b), the presence of metals did have an impact on the expression of plant growth-promoting activities. It also highlights that careful selection and investigation has to be performed, as not all metal-tolerant endophytes are ideal for application as biocontrol agents in metal-laden soil conditions.

\section{Conclusions}

The five endophytic isolates (Bipolaris sp. LF7, D. miriciae LF9, T. asperellum LF11, P. asparagi LF15, S. bicolor LF22) 
demonstrated the potential to stimulate plant growth in vitro assays. This is a desirable attribute for biocontrol agents, as application of these bioagents would not only suppress disease development, but also to promote growth and strengthen the plant to delay disease progression. However, their beneficial role was generally affected by metal stress, with decreased IAA and siderophore production, and ACC deaminase activities. Hence, the metal-tolerant attributes of endophytes did not necessarily render significant benefits to the host-plants. Nevertheless, of the two isolates tested, D. miriciae LF9 showed better potential and prospect for further development as a biocontrol agent.

\section{Acknowledgements}

The authors are grateful to Monash University Malaysia and the Tropical Medicine and Biology Multidisciplinary Platform for the funding and research facilities. The authors also thank Applied Agricultural Resources (AAR, Selangor, Malaysia) for supplying the ramets. The first author was a recipient of the PhD scholarship by Monash University Malaysia.

\section{References}

Acuna JJ, Jorquera MA, Martinez OA, Menezes-Blackburn D, Fernandez MT, Marschner P, Greiner R, Mora ML (2011) Indole acetic acid and phytase activity produced by rhizosphere bacilli as affected by $\mathrm{pH}$ and metals. J Soil Sci Plant Nutr 11:1-12.

Aguado-Santacruz GA, Moreno-Gomez B, Jimenez-Francisco B, Garcia-Moya E, Preciado-Ortiz RE (2012) Impact of the microbial siderophores and phytosiderophores on the iron assimilation by plants: a synthesis. Rev Fitotec Mex 35:9-21.

Babu AG, Kim SW, Yadav DR, Hyum U, Adhikari M, Lee YS (2015) Penicillium menonorum: a novel fungus to promote growth and nutrient management in cucumber plants. Mycobiol 43:49-56.

Babu AG, Shim J, Bang KS, Shea PJ, Oh BT (2014) Trichoderma virens PDR-28: A heavy metal-tolerant and plant growth-promoting fungus for remediation and bioenergy crop production on mine tailing soil. J Environ Manage 132:129-134.

Beneduzi A, Ambrosini A, Passaglia LMP (2012) Plant growth-promoting rhizobacteria (PGPR): Their potential as antagonists and biocontrol agents. Genet Mol Biol 35:1044-1051.

Carlos MHJ, Stefani PVY, Janette AM, Melani MSS, Gabriela PO (2016) Assessing the effects of heavy metals in
ACC deaminase and IAA production on plant growthpromoting bacteria. Microbiol Res 188:53-61.

Chen Y, Peng Y, Dai CC, Ju Q (2011) Biodegradation of 4-hydroxybenzoic acid by Phomopsis liquidambari. Appl Soil Ecol 51:102-110.

Chithra S, Jasim B, Mathew J, Radhakrishnan EK (2017) Endophytic Phomopsis sp colonization in Oryza sativa was found to result in plant growth promotion and piperine production. Physiol Plant 160:437-446.

Dimkpa CO, Svatos A, Dabrowska P, Schmidt A, Boland W, Kothe E (2008) Involvement of siderophores in the reduction of metal-induced inhibition of auxin synthesis in Streptomyces spp. Chemosphere 74:19-25.

Du RJ, He EK, Tang YT, Hu PJ, Ying RR, Morel JL, Qiu RL (2011) How phytohormone IAA and chelator EDTA affect lead uptake by $\mathrm{Zn} / \mathrm{Cd}$ hyperaccumulator Picris divaricata. Int J Phytoremed 13:1024-1036.

Glick BR, Cheng Z, Czarny J, Duan J (2007) Promotion of plant growth by ACC deaminase-producing soil bacteria. Eur J Plant Pathol 119:329-339.

Gravel V, Antoun H, Tweddell RJ (2007) Growth stimulation and fruit yield improvement of greenhouse tomato plants by inoculation with Pseudomonas putida or Trichoderma atroviride: possible role of indole acetic acid (IAA). Soil Biol Biochem 39:1968-1977.

Hassan SE (2017) Plant growth-promoting activities for bacterial and fungal endophytes isolated from medicinal plant of Teucrium polium L. J Advanced Res 8:687-695.

Hilbert M, Voll Lars M, Ding Y, Hofmann J, Sharma M, Zuccaro A (2012) Indole derivative production by the root endophyte Piriformospora indica is not required for growth promotion but for biotrophic colonization of barley roots. New Phytol 196:520-534.

Louden BC, Haarmann D, Lynne AM (2011) Use of blue agar CAS assay for siderophore detection. J Microbiol Biol Educ 12:51-53.

Machuca A, Milagres AMF (2003) Use of CAS-agar plate modified to study the effect of different variables on the siderophore production by Aspergillus. Lett Appl Microbiol 36:177-181.

Nascimento FX, Espada M, Barbosa P, Rossi MJ, Vicente CSL, Mota M (2016) Non-specific transient mutualism between the plant parasitic nematode, Bursaphelenchus xylophilus, and the opportunistic bacterium Serratia quinivorans BXF1, a plant-growth promoting pine endophyte with antagonistic effects. Environ Microbiol 18:5265-5276.

Naveed M, Hussain MB. Zahir ZA, Mitter B, Sessitsch A (2014) Drought stress amelioration in wheat through inoculation with Burkholderia phytofirmans strain PsJN. Plant Growth Regul 73:121-131.

Nieto-Jacobo MF, Steyaert JM, Salazar-Badillo FB, Nguyen DV, Rostas M, Braithwaite M, De Souza JT, Jimenez- 
Bremont JF, Ohkura M, Stewart A, Mendoza-Mendoza A (2017) Environmental growth conditions of Trichoderma spp. affects indole acetic acid derivatives, volatile organic compounds, and plant growth promotion. Front Plant Sci 8:102.

Patten CL, Glick BR (1996) Bacterial biosynthesis of indole3-acetic acid. Can J Microbiol 42: 207-220.

Rúa MA, McCulley RL, Mitchell CE (2013) Fungal endophyte infection and host genetic background jointly modulate host response to an aphid-transmitted viral pathogen.J Ecol 101:1007-1018.

Saleh SS, Glick BR (2001) Involvement of gacS and rpoS in enhancement of the plant growth-promoting capabilities of Enterobacter cloacae CAL2 and UW4. Can J Microbiol 47:698-705.

Sim CSF, Cheow YL, Ng SL, Ting ASY (2018) Discovering metal-tolerant endophytic fungi from the phytoremediator plant Phragmites. Water Air Soil Poll 229:68.

Sim CSF, Yue CS, Cheow YL, Ting ASY (2019a) Influence of metal stress on production of volatile inhibitory compounds by endophytes against Ganoderma boninense, Biocontrol Sci Technol 29(9):860-876.

Sim CSF, Cheow YL, Ng SL, Ting ASY (2019b) Antifungal activities of metal-tolerant endophytes against Ganoderma boninense under the influence of metal stress. Biol Control 130:9-17.

Sim CSF, Cheow YL, Ng SL, Ting ASY (2019c) Biocontrol activities of metal-tolerant endophytes against Ganoderma boninense in oil palm seedlings cultivated under metal stress. Biol Control 132:66-71.

Sirrenberg A, Goebel C, Grond S, Czempinski N, Ratzinger A, Karlovsky P, Santos P, Feussner I, Pawlowski K (2007) Piriformospora indica affects plant growth by auxin production. Physiol Plant 131:581-589.

Srivastav S, Yadav KS, Kundu BS (2004) Prospects of using phosphate solubilizing Pseudomonas as biofungicide. Indian J Microbiol 44:91-94.

Sukumar P, Legué V, Vayssiéres A, Martin F, Tuskan GA, Kalluri UC (2012) Involvement of auxin pathways in modulating root architecture during beneficial plant-microorganism interactions. Plant Cell Environ 36:909-919.
Ting ASY (2014) Biosourcing endophytes as biocontrol agents of wilt diseases. In Verma VC, Gange AC, Eds., Advances in Endophytic Research. Springer India. Pp. 283-300.

Verma VC, Singh SK, Prakash S (2011) Bio-control and plant growth promotion potential of siderophore producing endophytic Streptomyces from Azadirachta indica A. Juss. J Basic Microbiol 51:550-556.

Walpola B, Yoon MH (2013) In vitro solubilization of inorganic phosphates by phosphate solubilizing microorganisms. Afr J Microbiol Res 7:3534-3541.

Wu T, Xu J, Xie WJ, Yao ZG, Yang HJ, Sun CL, Li XB (2018) Pseudomonas aeruginosa L10: A hydrocarbon-degrading, biosurfactant-producing, and plant-growth-promoting endophytic bacterium isolated from a reed (Phragmites australis). Front Microbiol 9:1-12.

Yang SF, Hoffman NE (1984) Ethylene biosynthesis and its regulation in higher plants. Ann Rev Plant Physiol 35:155-189.

Yu XM, Ai CX, Xin L, Zhou GF (2011) The siderophoreproducing bacterium, Bacillus subtilis CAS15, has a biocontrol effect on Fusarium wilt and promotes the growth of pepper. Eur J Soil Biol 47:138-145.

Zarcinas BA, Ishak CF, McLaughlin MJ, Cozens G (2004) Heavy metals in soils and crops in southeast Asia. 1. Peninsular Malaysia. Environ Geochem Health 26:343-357.

Zhang YF, He LY, Chen ZJ, Wang QY, Qian M, Sheng XF (2011) Characterization of ACC deaminase-producing endophytic bacteria isolated from copper-tolerant plants and their potential in promoting the growth and copper accumulation of Brassica napus. Chemosphere 83:57-62.

Zúñiga-Silva JR, Chan-Cupul W, Loera O, Aguilar-López R, Xoconostle-Cázares B, Rodríguez Vázquez R (2015) In vitro toxic effects of heavy metals on fungal growth and phosphate-solubilising abilities of isolates obtained from Phragmites australis rhizosphere. Chem Ecol 32:49-67. 
